\title{
Thermal Analysis of Waste Heat Recovery Systems Using CFD
}

\author{
C. Ganesh ${ }^{1 *}$, M. Shivshankar ${ }^{2}$, P. Harisha ${ }^{3}$ \\ 1,2Department of Mechanical Engineering, Siddaganga Institute of Technology, Tumakuru, India \\ ${ }^{3}$ Department of Mechanical Engineering, Visvesvaraya Technological University Centre for PG Studies, \\ Mysuru, India
}

\begin{abstract}
The project statement is to optimize the heat transfer in a compact heat recovery unit (Heat Recovery and Emission Control Equipment - HREC) using CFD with application in day to day life. In general, the outgoing exhaust gasses are released to atmosphere at over temperature of the dew point of water vapor in waste gases. Recovering a portion of the waste heat enhances the efficiency of the equipment and as well reduce the emissions providing energy savings and green environment. In this study, the potential of recovering waste heat emitted by any heat generation units in common day to day life and in industry is considered. The Heat Recovery and Emission Control Equipment (HREC) acts an intermediate unit at the exit of hot gas generation unit \& feed water heating unit. As a result of the calculation, it was determined that recovery of the waste heat can be employed at many applications as like as a combustion air preheater by means of a recuperator.
\end{abstract}

Keywords: Waste heat, Recovery unit, CFD analysis.

\section{Introduction}

Now-a-days, due to the rapid population growth and industrial growth has immense effect on the usage of energy. Enormous amount of power is needed to be produced to meet the world's energy requirement. In doing so most of the power plants emits large amount of hot gases along with polluting agent. As the population increases, need for the vehicle is also increases hence more combustion engines to be produced and used to run a vehicle. During the process of power production, large amount of heat is liberated from the various processes and it is simply dumped into the nature without making use of it. Boilers, furnaces, ovens, processing plants and etc. are the various areas where we can get heat energy [1]. The dumped heat from these sources into the nature is called as waste heat. Waste heat from the sources is may be due to the thermodynamic limitations and economical factors related to the processing equipment. It is possible to get some usefulness from the waste heat by using special unit called as Waste heat recovery unit.

Generally, recovery of waste heat depends upon two important factors those are [1],

a) Quality of Heat losses

b) Quantity of Heat losses

\section{a) Quality of Heat Losses}

Depending upon the type of processes waste heat emitted from the various sources will of different temperature. Generally, we can get the heat in three grades that is high temperature grade heat, medium temperature grade heat and low temperature grade heat [2]. Waste heat harnessed from various processes can be used for the other processes such as space heating, combustion air preheating, preheating of boiler feed water and etc. quality of the heat depends upon the temperature grade of the obtained heat, hence it is necessary to know the temperature grades of waste heat followed by its usage for different processes.

\section{b) Quantity of Heat Losses}

In any heat recovery situation, it is essential to know the amount of heat recoverable and also how it can be used.

\section{A. Classification and Application of Waste Heat}

High Temperature Heat: Almost all the waste heat of high temperature grade is emitted from the direct fuel burning processes. Temperatures of waste hot gases emitted from the various industrial process equipment contains high quality of heat [2].

Medium Temperature Heat: The temperature of waste gases from process equipment are in the medium temperature range of $100-400^{\circ} \mathrm{C}$. This type of waste heat is extracted from the exhaust of directly fired process units.

Low Temperature Heat: This type of temperature range is usually not practical to extract work from the source, though the steam production may not be completely neglected if there is a need for low-pressure steam. Such temperature range may be useful in an auxiliary method for preheating purposes

The waste heat extracted can be used for space heating, preheating air, feed water heating and drying purposes etc.

\section{B. Selection of Waste Heat Recovery Unit}

There are many types of heat recovery units will be available, with this a common question will arises regarding the selection of suitable unit.

1) Understanding the process

Understanding the several techniques for the process is very

*Corresponding author: gcg600611@gmail.com 
much essential for development of a Waste Heat Recovery system. This can be achieved by reviewing the process flow sheets, layout diagrams, piping isometrics, electrical and instrumentation cable ducting etc. The complete study of these documents will help in identifying:

a) Sources and uses of waste heat.

b) Upset conditions occurring in the plant due to heat recovery.

c) Availability of space.

d) Any other constraint, such as dew point occurring in an equipment etc.

After identifying the source of waste heat and the possible use of it, the next step involved in the process is to select a suitable heat recovery system for extracting the waste heat.

2) Economic evaluation of waste heat recovery system

The evaluation of heat recovery system depends on financial factors such as investment cost, depreciation cost, payback period, rate of return etc. In addition to these factors, suggestions from experienced specialists and suppliers must be obtained for rational decision.

\section{Types of Heat Recovery Systems}

\section{1) Innovative heat recovery system}

The reason for this strategy is to improve the proficiency of a heat pipe exchanger by using a phase change material. The upper piece of the warmth pipe, is covered in a copper lodging which is loaded up with paraffin RT-21. The warmth pipes are normally made of copper material and they use water as the working liquid.

\section{2) Regenerative burners}

Regenerative and recuperative burners shown in figure 1 enhance energy productivity by consolidating heat exchanger surfaces to catch and utilize the waste warmth from the hot pipe gas from the ignition cycle.

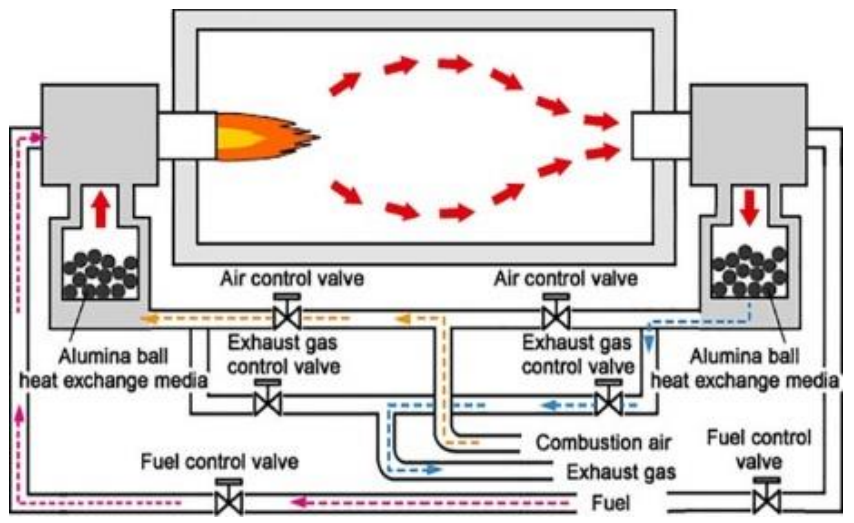

Fig. 1. Regenerative burners

\section{3) Plate heat exchangers}

Plate heat exchangers are the gadgets which are utilized to move heat starting with one liquid then onto the next to keep away from the cross pollution between the liquids. Between each two sequential plates there is a space or entry that has been actualized which makes the hot and cold liquids stream along and through the plane of the plates as shown in figure 2.

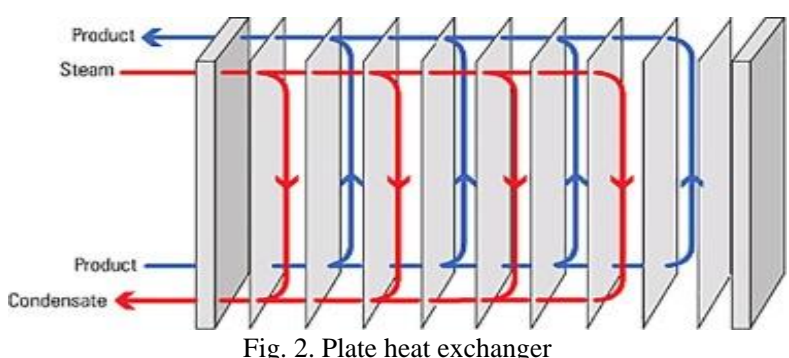

\section{Literature Review}

The ample quantity of heat is available from the various sectors and which can be utilized for the various processes by using a device called heat recovery unit [3], [4]. To analyses the flow behavior of heat around the device a special analytical tool called CFD can be used in various processes and studies [5][11]. For CFD analysis various models are available but RANS $\mathrm{K}-€$ model is selected as it is very simple for indoor and outdoor flow simulations [12]. We can handle various fluid flow conditions and can achieve better performance with least percentage of error by using K-€model. ANSYS software will be used for the characterization of meshing in CFD. Tetrahedral and hexahedral geometries are available for the meshing analysis both the geometries are having disadvantages in terms of time consumption factor.in order to compensate these disadvantages tetrahedral geometry will be considered for meshing analysis.it is also examined that heat transfer coefficient is different for different types of tubes arrangement.

\section{Objectives and Methodology}

\section{A. Objectives of the work}

The objective of the project is to be divided into two aspects,

1. Evaluate various application for such HREC Equipment with application to a. Domestic use b. Industrial scenarios.

2. Optimize the tube routing inside a HREC Equipment using CFD for maximum heat recovery by considering the tube layout submerged in feed water as in the case of a flue gas recovery unit. Tube arrangements are varied into multiple lay outing such as

a. Inline arrangement

b. U tube routing vertical plane

c. U tube routing horizontal plane

The approach followed in this investigation is to simulate the As-built condition to understand the flow behavior and thereafter suggest modification of the problematic area such that flow reversals are eliminated and heat transfer is optimized. Best tube layout is selected based on following criteria,

1. Optimum heat transfer

2. Minimum pressure loss

3. No flow abnormalities and reversals to mitigate noise \& enhance life.

\section{B. CAD Modelling}

The CAD Modeling of the heat recovery boiler is done by the top down approach, where the housing is modeled as shown in the figure and then the gas tubes are modeled with respect to the 
dimensions as mentioned above and with reference to the housing. The headers are modeled with the specified dimensions and according to the cases differently. The inlet and outlet water tubes are modeled with reference to the headers. The auxiliary water tubes arrangements are made differently with respect to the cases specified.

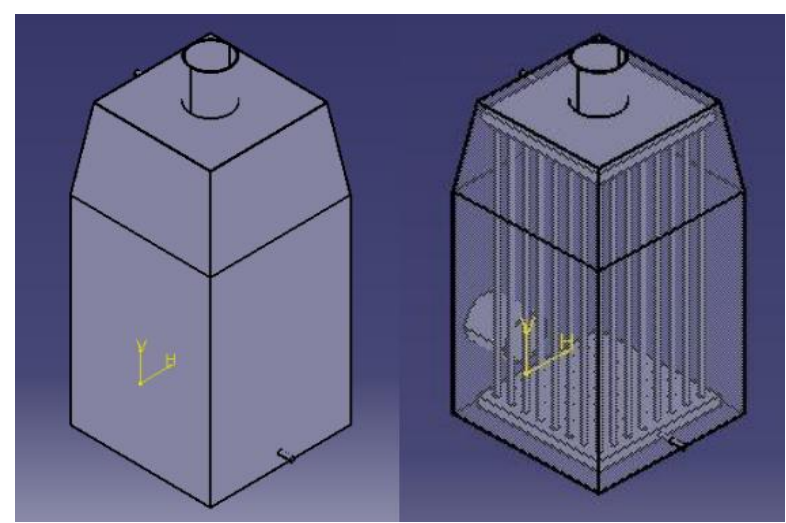

Fig. 3. CAD model of casing
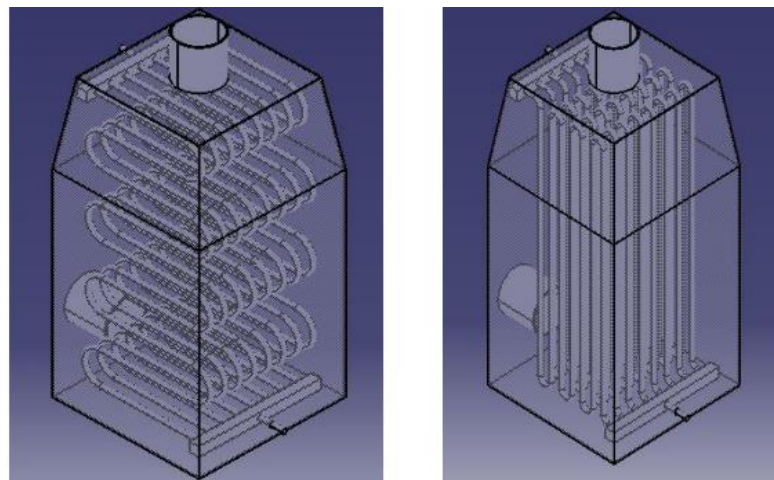

Fig. 4. Horizontal and vertical tube arrangement

The casing of heat recovery unit and straight inline arrangement of tubes is as shown in figure 3. horizontal tube arrangement and vertical tube arrangement model is sown in Figure 4. For all these three different types of tube arrangement an investigation is done to determine the maximum heat recovery arrangement.

\section{ANSYS Meshing}
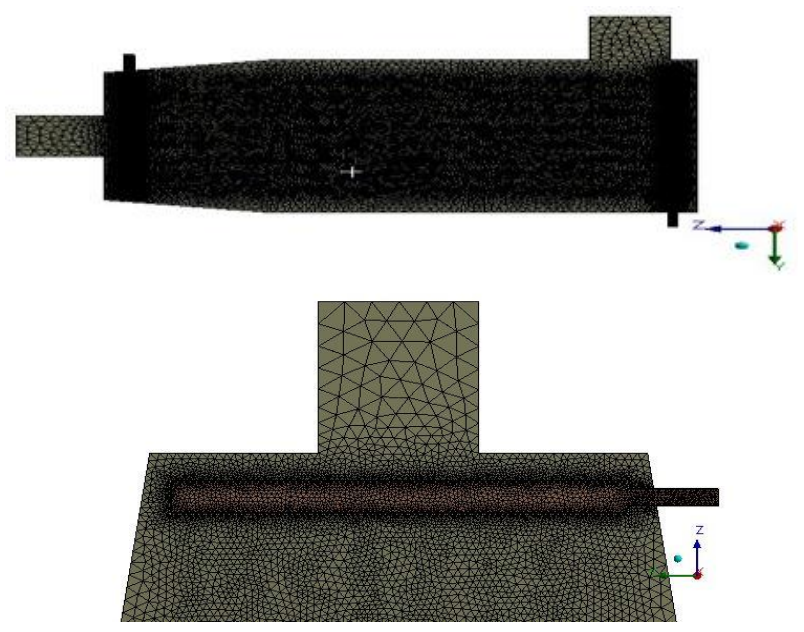

Fig. 5. Meshed model
Here tetrahedral meshes are generated for analysis. Global and local edge sizing was used to control the mesh generation. Face sizing option was also utilized. Local mesh sizing was applied at the tubes and the header to control the mesh generation. Total element count is around 600k. Element quality is measured in terms of skewness and orthogonal quality. It was found that quality lies in the acceptable range. The figure 5 shows the density of mesh elements. Fine elements are required near tube walls.

\section{Numerical Modelling}

This includes the geometry required for the simulation, mesh generation, case setup and solver settings. Case setup involves selection of mathematical models that governs the physics of the problem, defining material properties, cell zones and the boundary conditions. After the solution, the results were evaluated in the post-processing step which is discussed in the next chapter. The Fluent solver in ANSYS software is used for solving the problem which is based on Finite Volume Method (FVM).

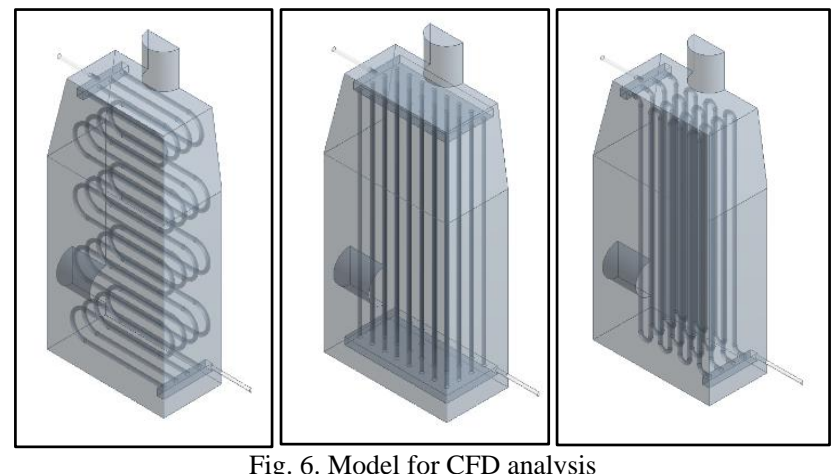

In figure 6 , it can be seen that only the half of the actual geometry is considered for CFD analysis. This is due to symmetry in the geometry as well as boundary conditions. This will help to reduce the mesh count as well as computational time.

\section{1) Materials used and their properties}

In the present case, the hot flue gas enters into the furnace at $750^{\circ} \mathrm{C}$ and 5 bar whereas the water enters the tube at $20^{\circ} \mathrm{C}$ and 0.5 bar. Therefore, the properties of fluids are evaluated at this temperature as shown below in table 1 .

Table 1

Properties of materials

\begin{tabular}{|l|l|l|}
\hline \multicolumn{1}{|c|}{ Properties } & \multicolumn{1}{c|}{ Water } & \multicolumn{1}{c|}{ Flue Gas } \\
\hline Density $\left(\mathrm{kg} / \mathrm{m}^{3}\right)$ & 998.435 & 0.51572 \\
\hline Viscosity $(\mathrm{kg} / \mathrm{m}-\mathrm{s})$ & 0.0010014 & 0.00004407 \\
\hline Thermal conductivity (W/m-k) & 0.5987 & 0.06902 \\
\hline Specific Heat $(\mathrm{J} / \mathrm{kg}-\mathrm{k})$ & 4183.24 & 1146 \\
\hline
\end{tabular}

\section{Results and Discussion}

In this section, the results from the CFD analysis for three configurations will be compared and the best tube design will be selected on the basis of the following factors:

- Highest heat transfer rate

- Highest heat exchange between fluids 
- Highest temperature rise in water

- Pumping power required in water tubes

Comparison Of Heat Transfer Rate

$\square$ Inline $\square$ Horizontal U-Tube $\square$ Vertical U-Tube 2636.16

314.63

Heat Transfer Rate (W/m2-k)

Fig. 7. Comparison of heat transfer rate

\section{Comparison Of Total Heat Transferred}

$\square$ Inline $₫$ Horizontal U-Tube $\square$ Vertical U-Tube

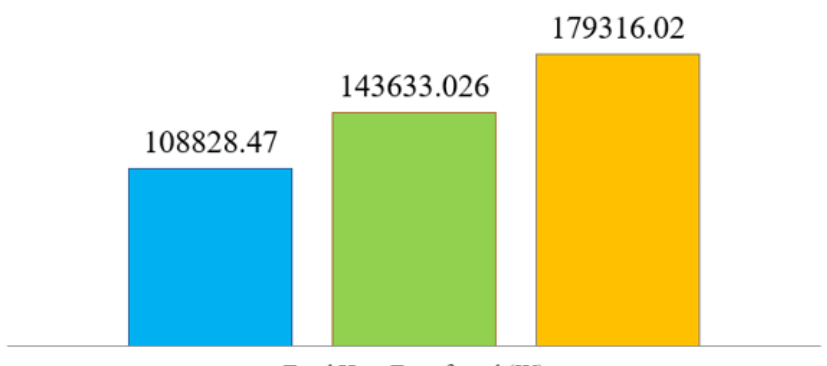

Total Heat Transferred (W)

Fig. 8. Comparison of total heat transferred

Comparison Of Water Temperature Rise

$\square$ Inline Tube $\square$ Horizontal U-Tube $\square$ Vertical U-Tube

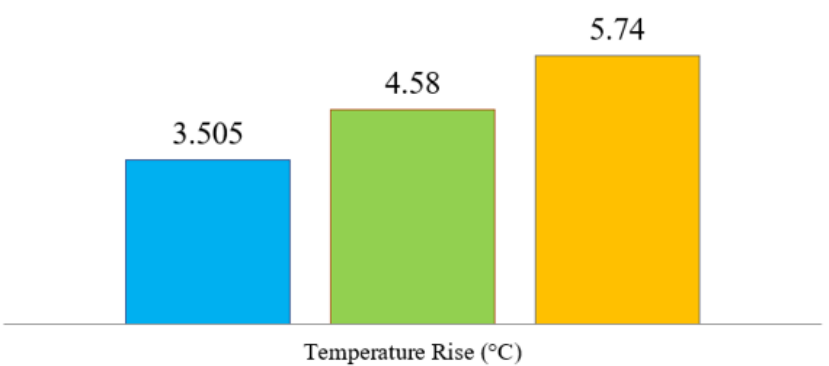

Fig. 9. Comparison of water temperature rise

\section{Comparison Of Pressure Drop}

$\llbracket$ Inline Tube $\quad$ Horizontal U-Tube $\square$ Vertical U-Tube 55204

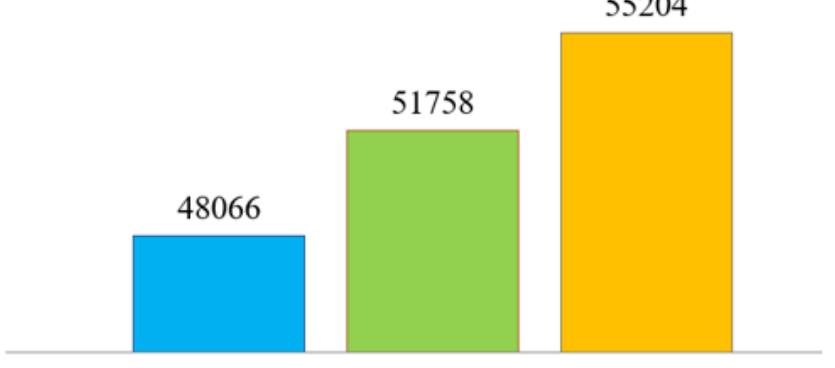

Pressure Drop $(\mathrm{Pa})$

Fig. 10. Comparison of pressure drop

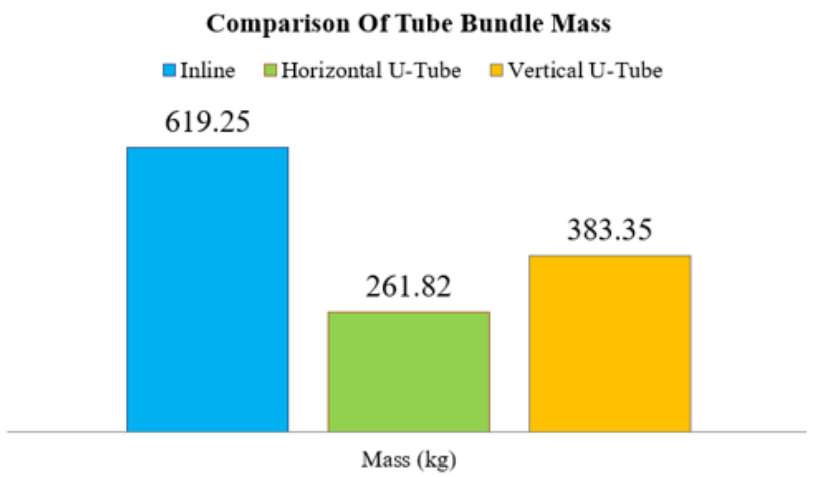

Fig. 11. Comparison of tube bundle mass

From the above charts, following important points were made:

- Horizontal U-tube configuration is best among the three configurations in terms of heat transfer rate. Its heat transfer coefficient is $2636.16 \mathrm{~W} / \mathrm{m}^{2}-\mathrm{k}$ which is $26.8 \%$ higher than the vertical U-tube configuration \& $561 \%$ higher than the inline-tube arrangement.

- Vertical U-tube configuration is best among the three configurations in terms of total heat transferred. Accordingly, it has highest rise in water temperature which is $5.74^{\circ} \mathrm{C}$. This temperature rise is $25.3 \%$ higher than the vertical U-tube configuration \& $63.8 \%$ higher than the inline-tube arrangement.

- In terms of pressure drop, inline configuration is good but it does not matter because its heat transfer rate is very low. However, the pressure drop in horizontal U-tube is $51758 \mathrm{~Pa}$ which is $6.7 \%$ lower than the vertical U-tube configuration.

- In terms of mass of the tube geometry, which includes tube bundle, inlet and outlet headers, configuration 2 is much lighter than the other two configurations. Its mass is $261.82 \mathrm{~kg}$ which is $46.42 \%$ lighter than vertical U-tube configuration and $136.5 \%$ lighter than the inline tube configuration.

\section{Conclusion}

In this research study, three configurations of heat recovery and emission control system (HREC) were numerically modeled using fluent solver in ANSYS 19.0. The heat recovery system is a type of heat exchanger which recovers heat from the hot flue gas and utilizes it to heat up the cold water. The objective was to optimize the tube routing inside a HREC Equipment using for maximum heat recovery. After simulating the three configurations it was observed that the inline-tube configuration has very low heat transfer rate as compared to horizontal and vertical U-tube configuration and also it has highest mass among the three configurations.

On comparing the horizontal and vertical tube configurations, it can be concluded that the horizontal U-tube configuration is better option on the basis of following points:

- It has $26.8 \%$ higher heat transfer rate than the vertical Utube configuration.

- Pressure drop in this arrangement of tube is $6.7 \%$ lesser 
than the vertical U-tube configuration.

- The mass is about $46.42 \%$ lower than the vertical U-tube configuration.

- The cost of material will be less for horizontal U-tube configuration.

- Total heat transferred in vertical U-tube is higher than the horizontal U-tube due to higher heat transfer area. But much higher total heat transfer can be achieved for horizontal U-tube configuration by making its heat transfer area equivalent to vertical U-tube configuration.

\section{References}

[1] R. Suryavanshi, and A. D. Pitale, "A Review on Waste Heat Recovery in Industries," in International Journal of Research in Advent Technology, vol. 5, no. 4, pp. 32.35, April 2017.

[2] Bureau of Energy Efficiency

[3] Y. P. Bhalerao, S. V. Patil, P. V. Vijay Babu, and S. J. Kulkarni, "Energy Retrofit Studies in Diethyl Thiophosphoryl Chloride (DETC) Plant," in International Journal of Chemical Engineering and Applications, vol. 2, no. 6, pp. 439-443, 2011.

[4] A. Piacentino, "Thermal analysis and new insights to support decision making in retrofit and relaxation of heat exchanger networks," in Applied Thermal Engineering, vol. 31, no. 16, pp. 3479-3499, 2011.
[5] M. H. Zawawi, A Saleha, et al., "A Review: Fundamentals of Computational Fluid Dynamics (CFD)," in AIP Conference Proceedings 2030, vol. 2030, no. 1, 2018.

[6] J. S. Shang, "Three decades of accomplishments in computational fluid dynamics," in Progress in Aerospace Sciences, vol. 40, no. 3, no. 3, 173197, April 2004.

[7] D. Adechy, and R. I. Issa, "Modeling of annular flow through pipes and T-junctions," in Computers and Fluids, vol. 33, no. 2, pp. 289-313, 2004.

[8] P. J. Stopford, "Recent applications of CFD modelling in the power generation and combustion industries," in Applied Mathematical Modelling, vol. 26, no. 2, pp. 351-374, February 2002.

[9] S. E. Kim and F. Boysan, "Application of CFD to environmental flows," in Journal of Wind Engineering and Industrial Aerodynamics, vol. 81, no. 1-3, pp. 145-158, 1999.

[10] G. Scott and P. Richardson, "The application of computational fluid dynamics in the food industry," in Trends in Food Science \& Technology, vol. 8, no. 4, pp. 119-124, April 1997.

[11] C. K. Harris, D. Roekaerts, F. J. J. Rosendal, F. G. J. Buitendijk, Ph. Daskopoulos, A. J. N. Vreenegoor, and H. Wang, "Computational fluid dynamics for chemical reactor engineering," in Chemical Engineering Science, vol. 51, no. 10, pp. 1569-1594, May 1996.

[12] L. Shao, and S. B. Riffat, "Accuracy of CFD for Predicting Pressure Losses in HVAC Duct Fittings," in Applied Energy, vol. 51, no. 3, pp. 233-248, 1995. 